\title{
LA RECEPCION DEL PENSAMIENTO NIETZSCHEANO EN EL SIGLO XX
}

Rafael del Hierro

Sin duda, la valoración de las interpretaciones que del "alegre mensajero" se han venido dando a lo largo del presente siglo necesariamente habrá de formar parte ya de una cierta interpretación de la filosofía de Nietzsche o, cuanto menos, habrá de depender de un cierto criterio interpretativo desde el que proceder a dicha valoración. Recíprocamente, por lo demás, toda interpretación supone ya de entrada una cierta valoración del resto de las interpretaciones. En este caso, ya se considere la valoración de las interpretaciones o la interpretación misma de la que aquélla forma parte o depende, en absoluto pretende esta breve contribución a los estudios nietzscheanos efectuar una valoración pormenorizada de la ingente bibliografía acumulada en tomo a Nietzsche ni la enormidad de superar el consiguiente relativismo interpretativo presentando sub specie aeternitatis una imagen objetiva y apta para todos los públicos que se correspondiera con la realidad de la filosofía de Nietzsche, puesto que la imagen resultante no dejaría de ser con todo relativa a la particular interpretación del que la presenta. Un posible criterio formal en la interpretación de la filosofía nietzscheana -que es el que habrá de orientar este trabajoconsistiría tan sólo en saber qué es prioritario en Nietzsche $y$, como consecuencia de ello, qué es subordinado, ya que parece ser una constante en los estudios nietzscheanos que se opte por privilegiar los aspectos menores de su filosofía, incluso marginales a ella o circunstanciales a la persona, como clave interpretativa para mostrar desde ahí la verdadera imagen de la obra y la personalidad del filósofo. En todo caso, y dando por sentada la imposibilidad de interpretación unívoca, independientemente de que estén bien o mal argumentadas, de que se sostengan o no ante la letra impresa de los escritos nietzscheanos, de que refleje o no

Éndoxa: Series Filosóficas, $n^{\circ} 4,1994$, UNED, Madrid:

Rafael del Hierro: La recepción del pensamiento nietzscheano en el s.xx.

pp. 233-253. 
con más o menos exactitud la doctrina, cada intérprete elaborará inevitablemente la particular interpretación que se merece.

Desde el comienzo mismo de su filosofía, el nombre de Nietzsche ocupa ya un lugar, si no sobresaliente, sí lo bastante preciso como para no poder hablar a este respecto de aislamiento o desconocimiento, y ello tanto en el ámbito artístico y literario como en el filosófico y filológico. A raíz de la publicación de El nacimiento de la tragedia, la polémica mantenida entre WilamowitzMöllendorff y Rohde, así como el apoyo público de Wagner, contribuyen sin duda a que ésta y las siguientes obras de Nietzsche no pasen del todo desapercibidas, particularmente entre los artistas y escritores, que muy pronto vieron en el estilo nietzscheano y en su total ausencia de jerga filosófica, así como en el carácter afirmativo de la doctrina y en su consecuente inmoralismo, un paso adelante respecto de Schopenhauer y, en cualquier caso, puentes tendidos hacia la esfera de su propia actividad. Puede decirse, sin embargo, que el inicio de la verdadera celebridad de Nietzsche coincide aproximadamente con el final de su producción filosófica, habiéndose de prolongar desde el primer estudio serio de su doctrina, en la primavera de 1888, a cargo de Georg Brandes ${ }^{1}$, hasta el final de la Gran Guerra. La polémica suscitada en torno a la enfermedad de Nietzsche, con las posturas enfrentadas de Möbius, el médico intérprete, y de Elisabet Förster-Nietzsche, la hermana solícita, no hace sino atraer aún más el interés de los escritores y seguir justificando el esencial alejamiento de los filósofos, a pesar de las desinteresadas muestras de curiosidad que se le brindan por doquier. Así, mientras que nadie ha podido

${ }^{1}$ F. Nietzsche, Eine Abhandlung über aristokratichen Radicalismus (1888), en "Deutsche Rundschau", XVI (1890), pp. 53-89. Más tarde será recogido en Menschen und Werken, Frankfort, 1895. La edición danesa es de 1889. 
todavía señalar un solo "discípulo" de Nietzsche a lo largo de las tres décadas que siguieron el cese de su producción filosófica, son numerosos los escritores a quienes, con razón o sin ella, frecuentemente sin ella, se les ha relacionado con alguna de las múltiples facetas de la filosofía nietzscheana, como son los casos de Georges, Rilke, Musil, Mann, Hesse, Zweig, Jünger, Kafka, Strindberg, D. H. Lawrence, Gide, Danunzio, Papini e, incluso, Azorín y Baroja, los escritores de la generación del 98 más sensibles al "nihilismo" y a la "crítica". En cualquier caso, y al margen de lo acertado o desacertado de las interpretaciones, la repercusión de las obras de Nietzsche es, en esta época, un acontecimiento cultural europeo, no sólo filosófico y no sólo alemán. Por lo que respecta a los primeros estudios filosóficos, éstos varían entre las preocupaciones de indole biográfico y las propiamente doctrinales, muy en particular las concernientes a la moral ${ }^{2}$. A pesar de la candidez interpretativa de la mayor parte de ellas, quizá no sería exagerado decir que estas primeras aproximaciones a la obra de Nietzsche son notablemente más sinceras y honestas que las que tendrán lugar a partir de los años treinta, pues no tratan de escamotear en ningún caso los aspectos más indigeribles de la filosofía nietzscheana, aun cuando sean convenientemente refutados al percibir con toda claridad que la celebración dionisíaca de la existencia siempre habrá de suponer un peligroso inmoralismo que la buena sensibilidad filosófica no parece estar dispuesta a tolerar.

Más tarde, con la pretensión de acomodar la filosofía nietzscheana a las particulares características de la filosofía de los sucesivos intérpretes, milagrosamente deudores de las enseñanzas de Zaratustra todos ellos, aquella candidez dará paso a sutiles e insospechados descubrimientos que nadie había sido capaz de leer hasta entonces en los libros de Nietzsche, a la vez que la sinceri-

${ }^{2}$ Debido a las características de este trabajo, no es posible remitir aquí a los autores y títulos que conforman la amplia bibliografía secundaria de Nietzsche en este periodo. Baste con recordar los nombres de L. Andreas-Salomé (1894), A. Riehl (1897), H. Vaininger (1902), R. Eisler (¿902), O. Ewald (1903), A. Drews (1904) y C. Joël (1905) o G. Simmel (1907). 
dad y honestidad de tan sagaces intérpretes a la hora de presentar no ya su propia interpretación, sino tan sólo los principales temas de la filosofía nietzscheana, comenzará a trocarse en franca mendacidad $y$, en algún que otro caso, en abierta tomadura de pelo para los lectores, lo que en absoluto es una objeción para que se reconozcan en estos estudios los valores y cualidades inherentes a la propia filosofía del intérprete en cuestión. Las empresas de E. Bertram, L. Klages, A. Baeumler, K. Löwith, K. Jaspers y, sobre todo, M. Heidegger, se han esforzado en la medida de sus respectivas fuerzas, y atendiento a intereses muy distintos, justamente los de cada intérprete, por actualizar el pensamiento de Nietzsche o, cuanto menos, por adaptarlo a las condiciones de sus repectivas preocupaciones filosóficas: la reconstrucción mitológica del pensamiento nietzscheano convertido en "leyenda" (Bertram) ${ }^{3}$, la psicología del autoengaño que el propio Nietzsche, descubridor descubierto, aplica en su propia y contradictoria filosofia (Klages) ${ }^{4}$, la voluntad de poder convertida en criterio de justicia política nacional-socialista (Baeumler) ${ }^{5}$, el eterno retorno como la insatisfactoria fórmula teológica propuesta por Nietzsche para armonizar al hombre con la naturaleza (Löwith) ${ }^{6}$, las doctrinas nietzscheanas del superhombre, de la voluntad de poder y del eterno retorno, como planteamientos esencialmente trascendentales que van más allá del expreso intento de Nietzsche por rechazar precisamente toda trascendencia (Jaspers) ${ }^{7}$, el acabamiento de la metafísica tradicional, y no la "superación", que el inversor del platonismo representa se deduce del hecho de haber pensado Nietzsche la volutad de poder como la essentia del ente y el eterno retorno como su existentia, con lo que se olvida del ser y su distinción

\footnotetext{
${ }^{3}$ Nietzsche, Versuch einer Mythologie, Berlin, 1918.

4 Die psychologischen Errungenschaften Nietzsches, Leipzig, 1926.

5 Nietzsche, der Philosoph und Politiker, Leipzig, 1931.

${ }^{6}$ Nietzsches Philosophie der ewigen Wiederkehr des Gleichen, Berlin, 1935; 2" ed., ampliada y corregida, Stuttgart, 1956.

${ }^{7}$ Nietzsche. Einführung in das Verständnis seines Pholosophierens, Berlin, 1936.
} 
oi.tológica con el ente (Heidegger) ${ }^{8}$. Todas estas célebres interpretaciones, que pueden ser muy apreciables y útiles, por lo demás, para conocer las filosofías de sus respectivos intérpretes, en tanto que la acomodación del pensamiento nietzscheano a la estructura de sus propios pensamientos dice más de éstos que de aquél, sólo tienen en común la diferente y siempre original manera de escamotear la filosofía trágica de Nietzsche de la vista del lector, el hecho de no haber tenido en cuenta para nada lo que realmente Nietzsche ha dejado escrito en todas y cada una de sus obras: que no hay más que una única y muy cruda realidad, que no hay ni mundo verdadero ni mundo aparente, imaginaria dicotomía elaborada para desdoblar el mundo y cocinar una de sus partes, que la contundente realidad del mundo carece de todo contacto con la verdad, no porque el ser se reduzca al valor, horrendo antropomorfismo, sino porque es la verdad demasiado humana la que se reduce al valor. Si el superhombre es el sentido de la Tierra, ello es porque ni la Tierra ni el hombre tienen sentido, porque aquélla no puede recibir el sentido de quien, a su vez, espera recibirlo de aquélla. El espíritu libre, la creación, el ateísmo y el inmoralismo se siguen de ahí.

Un tercer período en la historia de las interpretaciones de la filosofía trágica de Nietzsche es el que tiene lugar después de la segunda guerra mundial y hasta los años sesenta. Es quizás el menos fructífero y el de menor influencia, por cuanto suele presentar en desafortunada síntesis las características de los dos momentos anteriores, tratando de compensar el dañino y sobrehumano inmoralismo de Nietzsche con su bella metafísica trascendente, o viceversa. En efecto, la lectura de Nietzsche y la valoración resultante se realizará preferentemente a partir de ciertas

${ }^{8}$ Nietzsche, 2 vols., Pfullingen, 1961. Recoge una serie de cursos impartidos en Friburgo entre los años 1935 y 1940, así como escritos del período 1939-1946. Véase tambien "Nietzsche Wort: Gott ist tot" (1936-1940), en Holzwege, Frankfurt, 1950 Itrad. cast., "La frase de Nietzsche: "Dios ha muerto"'", en Sendas perdidas, Ed. Losada, Buenos Aires, 1960, págs. 174-221]; y "Wer ist Nietzsches Zaratustra?" (1953), en Vorträge und Aufsätze, Pfullingen, 1954. 
claves interpretativas que carecen, desde luego, de la más mínima relación con su filosofía, pero que al parecer preocupan mucho a los intérpretes. Se trata de saber si Nietzsche debe ser exculpado o no de los cargos que se le imputan por haber facilitado la tarea ideológica a los intelectuales del nazismo, entrando así a formar parte de uno de los temas más recurrentes de la filosofía alemana desde entonces, su principal y casi único tema obsesivo, a saber, el pensamiento de la mala conciencia histórica, justamente el menos adecuado para que la libertad de espíritu pueda tratar con un "espíritu libre". También es el momento, después de Jaspers, de saber si Nietzsche puede ser interpretado o no en clave existencialista, esto es, trascendentalista, e incluso de saber si puede ser considerado o no un buen cristiano, no tanto en un sentido paulino -pues el Anticristo no deja al respecto la menor sombra de duda, por muy escéptico que se sea-, cuanto en su verdadero sentido, el más auténtico y originario, el heterodoxo, el más próximo al mensaje real de Jesús de Nazaret, el Dios vivo.

Al margen de lo acertado o no de los estudios nietzscheanos de este período, los extremos de sinceridad y mendacidad, de acercamiento $y$ alejamiento, de esfuerzo interpretativo y de gratuito asalto irracionalista a la docrina, podrían ilustrarse, respectivamente, con las posturas de E. Fink y de G. Lukács. La tarea de Lukács $^{9}$ no puede ser más fácil. Basta con dividir la historia de la filosofía y de la humanidad en dos períodos excluyentes, separados por su correspondiente chorismós: a un lado, el burgués; al otro, el revolucionario. Así, su interpretación de Nietzsche no hace en el fondo sino parafrasear la de Heidegger, bien entendido que donde éste dice "metafísica" aquél dirá "burgués". Nietzsche será, pues, el que lleve la ideología burguesa a su acabamiento irracionalista. En cuanto al estudio realizado por Fink ${ }^{10}$, uno de los pocos intérpretes que parece haber leído

9 Die Zerstörung der Vernunft, Berlin, 1956.

${ }^{10}$ Nietzsches Philosophie, Stuttgart, 1960. [Trad. cast., La filosofía de Nietzsche, Alianza Editorial, Madrid, $1976^{3}, 1^{*}$ ed., 1966.] 
realmente los libros escritos y publicados por Nietzsche, puede decirse que, aun estando en la estela heideggeriana, resulta estar bastante bien escrito, esto es, resulta ser muy inteligible e inteligente, probablemente uno de los mejores estudios introductorios a la obra de Nietzsche que se hayan realizado hasta la fecha, lo que no deja de ser una rareza visto el formidable relativismo interpretativo que suscita la doctrina. Ahora bien, como ya sucediera en Löwith, Jaspers o Heidegger, también Fink considera que Nietzsche no supera la metafísica con sus fórmulas "metafísicas": la muerte de Dios, el superhombre, la voluntad de poder y el eterno retorno. Esta interpretación sólo puede defenderse, en primer lugar, si se pone en tela de juicio, como hace Fink, la validez del método genealógico, esto es, la reducción de las verdades y juicios de los filósofos a los valores y prejuicios de los que emanan todos ellos, en suma, la reducción de la verdad al valor. $Y$ en segundo lugar, si de esta supresión de la verdad como aletheia del ser patraña filosófica por excelencia que no hace sino dar la vuelta al prejuicio de la verdad como adecuatio, más inteligible y científico, pero menos poético y mistérico, aunque en ambos casos con la misma pretensión de "racionalidad", y ello para seguir manteniendo una misma duplicación del mundo, esto es, una misma diferencia ontológica entre lo realmente existente y la nada, entre las cosas y la razón de las cosas- se infiere, como hacen Heidegger, Fink y tantos otros metafísicos, no se sabe muy bien por qué motivos, que Nietzsche concibe la realidad de las cosas o, simplemente, el ser como valor. Sin embargo, a pesar de haber realizado su interpretación desde una perspectiva metafísica, razón por la cual los principales conceptos nietzscheanos no podrán entenderse en ningún caso como lo que son, a saber, fórmulas filosóficas que aluden simplemente a la realidad, y no al mundo verdadero ni al aparente, esto es, a la duplicidad del mundo inherente a toda metafísica, Fink polemiza ya al final de su estudio con la interpretación de Heidegger -y con la suya propia- al preguntarse si la cautividad en la metafísica es total en el caso de Nietzsche o si, por el contrario, puede entreverse algún aspecto de la doctrina que 
lo libere de esa prisión. "Un inicio no-metafísico de filosofía cosmológica se encuentra en su idea del "juego". Ya desde sus primeros escritos se mueve Nietzsche en la dimensión misteriosa del juego, en su metafísica de artista, en su heraclitismo de niño que juega con el mundo, niño que es Zeus, el pais paizon (...) Sólo allí donde el nacimiento y desaparición de las figuras finitas y temporales son experimentados como baile y como danza, como juegos de dados de contingencias divinas, recubiertas por el cielo "inocencia" y el cielo "azar", (...) puede el hombre, en su productividad lúdica, sentirse semejante a la vida del todo, sentirse entregado al juego del nacimiento y la muerte de todas las cosas e inserto en la tragedia y la comedia del existir humano. El mundo juega, juega como el fondo dionisíaco que produce el aparente mundo apolíneo de las formas existentes, y que "con golpes de látigo lleva las cosas finitas hacia el pasto"11; juega configurando y destruyendo, entrelazando la muerte y el amor, más allá del bien y del mal, más allá de toda estimación axiológica, pues todos los valores aparecen sólo en el seno de este juego. ${ }^{.12}$ Corresponde, sin duda, al propio Fink la ingrata tarea de armonizar coherentemente esta idea de "juego" apenas reseñada al final de su estudio y expuesta de forma aislada, con la supuesta pertenencia a la metafísica de los conceptos fundamentales de la filosofia de Nietzsche. Asimismo convendría saber qué significa propiamente, en Heidegger, en Fink y en tantos otros metafísicos, no ya el concepto mismo de metafísica, sino el de una filosofía no-metafísica, esto es, qué significaría para ellos una filosofía que hubiera "superado" la metafísica. ¿No será tan sólo una nueva manera de entender la vieja metafísica y el desdoblamiento del mundo que le es inherente?

A partir de 1956, con la edición de K. Schlechta, y de 1967 y siguientes, con la nueva edición de Colli-Montinari, ya no hay excusas para seguir interpretando "sistemáticamente" el pensa-

\footnotetext{
${ }^{11}$ Heráclito, Fragm. B 11 (Diels).

${ }^{12}$ Op. cit., p. 223-224.
} 
miento de Nietzsche en función de un libro que no existe ni nadie ha escrito jamás, pero al que muchos han dado en considerar la obra fundamental de Nietzsche, como si las muchas y buenas obras realmente escritas por él no tuviesen más valor que el de prefigurar esa colección de dispersos apuntes personales que lleva por nombre La voluntad de poder. Sin embargo, con mayor o peor fortuna, las cosas no parecen haber cambiado un ápice en las interpretaciones que tienen lugar a partir de los años sesenta. La única novedad la representa el hecho de haber pasado a Francia el foco principal de atención sobre la filosofía de Nietzsche, circunstancia ésta que debe ser puesta en relación con las características más sobresalientes de la filosofía francesa de los últimos treinta años. En general, cabe decir que a la ya institucionalizada interpretación heideggeriana se le habrá de unir, siempre con una finalidad "transgresora" -unas veces relativa a la metafísica de la ausencia, otras veces en función de un espíritu revolucionario más o menos programático-, una cierta aureola de escándalo metafísico y moral muy bien recibido y mejor armonizado con toda suerte de influencia (hegeliana, marxista, psicoanalítica, fenomenológica, analítica, hermenéutica, etc.), que no hace sino contribuir a santificar las más insospechadas empresas filosóficas e intelectuales del momento, por muy alejadas que estén de las preocupaciones de Nietzsche. Si los estudios nietzscheanos de la primera época solían adoptar la forma "no, aunque...", y los del periodo intermedio la del "sí, pero...", ahora la tendencia será la de recoger aquel "no" y este "pero" para formar en una alabanza superior, que recoge todo lo censurable, un "sí" que más parece un "no" a la filosofía afirmativa de Nietzsche. Por lo demás, apenas puede encontrarse un sólo pensador francés digno de tal nombre -aunque en Europa ya sean legión los indignos que, como micos, han aprendido a imitar el gesto- que no invoque el papel relevante de Nietzsche en la gestación de su propia filosofía y, por añadidura, en la actual crisis del pensamiento occidental e, incluso, en la sempiterna decadencia de la civilización. No se trata de un renacimiento del interés por Nietzsche, puesto que en absoluto 
había muerto o disminuido, sino tan sólo de una etapa más en la historia de las interpretaciones que tiene como nuevo parámetro las circunstancias de la filosofía francesa de este último periodo.

Aunque muy pronto aparecen en Francia trabajos biográficos, como es el caso de los ya célebres de D. Halévy ${ }^{13}$ y de $\mathrm{Ch}$. Andler $^{14}$, o estudios comparativos con otras figuras de la cultura fracesa, tales como Stendhal o Bizet ${ }^{15}$, incluso análisis doctrinales de su obra, entre los que se encuentran los de $\mathrm{H}$. Lichtenberger ${ }^{16}$, J. de Gaultier ${ }^{17}$, A. Fouillée ${ }^{18}$, T. Maulnier ${ }^{19}$ o H. Lefebvre ${ }^{20}$, probablemente sea Georges Bataille ${ }^{21}$ en quien ha de recaer el mérito de haber inaugurado - $y$, hasta cierto punto, haber popularizado- un nuevo modo de entender a Nietzsche que, con pocas variaciones académicas, según las diferentes escuelas, es el que mayoritariamente perdura en la actualidad, tanto entre los filósofos e intelectuales en particular como entre el público culto y los estudiantes de letras en general. Mil afirmaciones y dos mil negaciones -de las atrevidas, las que tienen voluntad de primicia y chocante originalidad-jalonan su libro como si fueran palmarias evidencias que no admiten la menor discusión. Quizá se deba a que Bataille no pertenezca a la honorable estirpe de los escepticos,

\footnotetext{
${ }^{13}$ La vie de Nietzsche, Paris, 1909; nueva edición, reelaborada, Nietzsche, Paris, 1944.

${ }^{14}$ Nietzsche. Sa vie et sa pensée, 6 vols., Paris, 1920-1931; nueva reedición en 3 vols., Paris, 1958.

${ }^{15}$ A este respecto pueden consultarse Bianquis, G., Nietzsche en France, Paris, 1929; Williams, W. D., Nietzsche and the French, Oxford, 1952; y Boudot, P., Nietzsche et l'au-delà de la crise. Nietzsche et les écrioains français de 1930 à 1960, Paris, 1970.

${ }^{16}$ La philosophie de Nietzsche, Paris, 1898. [Trad. cast., La filosofia de Nietzsche, Ed. Daniel Jorro, Madrid, 1910.]

${ }^{17}$ De Kant à Nietzsche, Paris, 1900; Les maîtres de la pensée antichrétienne: Nietzsche, Paris, 1926.

${ }^{18}$ Nietzsche et l'inmoralisme, Paris, 1902.

${ }^{19}$ Nietzsche, Paris, 1933.

${ }^{20}$ Nietzsche, Paris, 1939. Véase también Hegel, Marx, Nietzsche ou le royaume des ombres, Paris, 1975. [Trad. cast., Hegel, Marx, Nietzsche o el reino de las sombras, Siglo XXI, Madrid-México-Buenos Aires, 1976.]

${ }^{21}$ Sur Nietzsche. Volonté de chance (1944), Ed. Gallimard, 1967. [Trad. cast., Sobre Nietzsche. Voluntad de suerte, Ed. Taurus, Madrid, 1972.]
} 
lo que explicaría, por lo demás, la buena acogida de esta brillante manera de leer a Nietzsche. Pero a ello hay que añadir lo más importante, la posición teórica desde la que se lee a Nietzsche: un cierto surrealismo de posguerra -mitad adolescente, mitad romántico, enteramente sentimental y pasivo, aunque ahora con un punto de temor no fingido que deja bien visible el tradicional carácter afectado de la moral surrealista-. Como es bien sabido, por pereza o por impotencia, el esteta surrealista se deleita en llevar la contraria a los valores en curso, se orienta con la reactiva transgresión de lo instaurado e, incluso, se complace cargando sobre sí los peores epítetos ya institucionalizados. Atendiendo a ese patrón, no duda Bataille un instante en aplicar este victimismo temeroso al propio Nietzsche. "Creo útil disipar un equívoco: Nietzsche sería el filósofo de la "voluntad de poder", como tal se daba, como tal se le recibió. Yo creo que es, más bien, el filósofo del mal (...) Si no fuera así, ¿cómo explicar este pasaje? "EL CORRUPTOR DEL GUSTO.- A: ¡Eres un corruptor del gusto! -así se dice en todas partes-. B: ¡Desde luego! Yo le corrompo a todo el mundo el gusto de su propio partido -esto ningún partido me lo perdona-." (LA GAYA CIENCIA, 172)"22 Lo que este pasaje no explica en ningún caso es por qué hay que asociar el mal con el solitario y el bien con los rebaños, como hace Bataille y todo buen moralista, por qué hay que mantener la divina gramática, por qué hay que caer del lado demoníaco. Nietzsche, al parecer, nunca habría aconsejado al filósofo que se situase más allá del bien y del mal, sino más acá, concretamente en el mal, eso sí, con buena voluntad, ya que la mala caerá por definición del lado del bien. El caso es acusar. Nietzsche sería, según esta perspectiva transgresora, un pensador maldito, el primer pensador en haber llevado a la filosofía las mismas preocupaciones sacrílegas -en el fondo, sagradas- que ya habían manifestado algunos escritores malditos -en el fondo, benditos- como Sade, Baudelaire o Lautréamont, todos ellos "prójimos", como diría Klossowski, de los nuevos heraldos de la

${ }^{22}$ Op. cit., p. 17 
transgresión. Antes se trataba de saber, entre otras cosas, si Nietzsche podría o no ser considerado un buen cristiano, un autentico cristiano partidario de Jesús; ahora, a partir de Bataille y del espíritu de los sesenta, se tratará de saber, entre otras cosas, si Nietzsche puede ser considerado un chico malo, esto es, un buen chico transgresor capaz de tirar la primera piedra.

De entre las numerosas y muy variadas interpretaciones que han tenido lugar en Francia durante las últimas tres décadas, desde la de Gilles Deleuze hasta la de Clément Rosset -de las que se hablará más adelante-, pasando por las de $\mathrm{M}$. Blanchot, $\mathrm{M}$. Foucauit, P. Klossowski, J. Derrida, B. Pautrat, F. Rey o J. Granier, sobradamente conocidas todas ellas ${ }^{23}$, quizá pudiera decirse sin temor a equivocarse demasiado que sólo las dos primeras se preocupan por analizar los aspectos esenciales de la filosofía de Nietzsche a partir del conjunto de la obra del autor, y no por especular acerca de aspectos puramente marginales, subalternos, episódicos o inexistentes de su filosofía, y casi siempre a partir de textos traídos por los pelos, muchas veces textos póstumos utilizados como borrador o desechados para la publicación, que no sólo son leídos con la debida descontextualización para que no guarden la más mínima relación con la filosofia nietzscheana, sino que además suelen ponerse a trabajar para una causa indiferente, diferente o contraria a la filosofía trágica del discípulo de Dioniso. En cualquier caso, sólo las interpretaciones de Deleuze y de Rosset parecen haber entrado de lleno en terreno nietzscheano, pudiendo incluso decirse que son las dos únicas, en Francia y en el presente siglo, que se han limitado a presentar su filosofía desde planteamientos muy cercanos (Deleuze) o idénticos (Rosset) al propio Nietzsche, razón por la cual ni se neutraliza su filosofía con consideraciones marginales a al autor y relativas casi siempre a la filosofía del lenguaje o a las ciencias humanas, ni se tiene necesi-

\footnotetext{
${ }^{23}$ Véanse también, de varios autores, los trabajos recogidos en Nietzsche, actas del VII coloquio filosófico internacional de Royaumont (4-8 de julio, 1964), Fondation Royaumont, Paris, 1967; y Nietzsche aujourd hui?, actas del coloquio internacional de Cérisy-La-Salle (julio, 1972), Paris, 1973.
} 
dad de afirmar o negar nada relativo a las ciencias políticas, morales y religiosas.

En el muy completo estudio de la filosofía de Nietzsche elaborado por Deleuze ${ }^{24}$, probablemente más citado que leído y más parafraseado que comprendido, como se deduce del casi nulo influjo que en realidad parece haber ejercido entre los nietzscheanos de todo tipo, quizá porque en él no aparece de modo explícito ningún elemento que relacione la filosofía nietzscheana con las preocupaciones de la filosofía contemporánea, "esa extraña mezcla de ontología y antropología, de ateísmo y de teología"25, Nietzsche aparece como un pensador trágico, anti-metafísico y antidialéctico por el simple y raro hecho de haberse atrevido a leer lo que el filósofo ha escrito, de haberse atenido a esa lectura teniendo delante todos los escritos del filósofo, de no aventurarse a especular más allá de lo dicho por Nietzsche mismo, de no extraer originales y atractivas conclusiones no autorizadas por el propio Nietzsche, en suma, de no querer convencer a los lectores de lo actualísima que podría ser la filosofía de Nietzsche si cayera en manos de la filosofía actual. "En proporciones variables, un poco de espiritualismo cristiano, un poco de dialéctica hegeliana, un poco de fenomenología como escolástica moderna, un poco de fulguración nietzscheana, forman extrañas combinaciones. Vemos a Marx y a los presocráticos, a Hegel y a Nietzsche, darse la mano en un corro que celebra la superación de la metafísica e incluso la muerte de la filosofía propiamente dicha (...) En este libro hemos intentado romper peligrosas alianzas. Hemos imaginado a Nietzsche retirando su apuesta de un juego que no es el suyo. Nietzsche decía a propósito de los filósofos y de la filosofía de su tiempo: pintura de lo que nunca ha sido creído. Quizá también lo diría de la filosofía actual." ${ }^{16}$

${ }^{24}$ Nietzsche et la philosophie, P.U.F., Paris, 1967. [Trad. cast., Nietzsche y la filosofía, Ed. Anagrama, 1971.]

${ }^{25}$ Op. cit., ed. cast., p. 271.

26 Ibid. 
Debido a la escasa atención concedida a la interpretación de Rosset, muy en consonancia con la casi nula atención que a su propia obra le dedica toda esa legión de "nietzscheanos" que en los últimos treinta años parecen haber ocupado toda la redondez de la Tierra, cabría hacer mención especial a su particular aportación a los estudios nietzscheanos y analizar con cierto detalle los principales temas desarrollados por Rosset. Sin embargo, dada la brevedad de este estudio, sólo es posible reseñar el sentido de su contribución. Más por confluencia que por influencia, más por coincidencia que por incidencia, la repercusión de los escritos nietzscheanos es nuclear, de principio a fin, en la filosofía de Rosset. Desde su primera obra, que lleva justamente por título una expresión que ya siempre irá unida al visionario de Sils-Maria, La filosofía trágica, hasta la exposición del modo resueltamente afirmativo con el que Nietzsche hace suyo el "milagro griego", en Principios de sabiduria y locura, pasando por todas y cada una de sus obras, Nietzsche es el único pensador que aparece siempre, no como un maestro ante su discípulo -pues la doctrina no es enseñable y el lenguaje de Rosset jamás es esotérico-, ni como una voz que otorga autoridad -sumisión que equivale sin más a dimisión-, ni siquiera como el mejor referente filosófico -forma ordinaria de llamar, salvo traición, a la desigualdad jerárquica ya mencionada-, sino tan sólo como el principal compañero de viaje, a lo sumo, como el hermano mayor, que repite una misma travesía. Así, no deja de ser coherente que la constante presencia nietzscheana en las obras de Rosset haga del todo innecesario elaborar tempranamente un análisis pormenorizado de la propia filosofía de Nietzsche. No debe sorprender en absoluto que haya que esperar hasta 1981 para ver publicados los primeros escritos sobre Nietzsche, recogidos más tarde en La fuerza mayor ${ }^{27}$. Varias consideraciones apoyan esta tesis de la innecesariedad unida a la presencia. En primer lugar, la forma misma de su publicación y el sencillo título que engloba a los artículos -"Notas sobre Nietzsche"-,

${ }^{27}$ La force majeure, Les Éditions de Minuit, París, 1983. 
subordinado al título genérico de la obra en la que se insertan - La fuerza mayor-, no parece indicar que se busque ninguna notoriedad especial. En segundo lugar, no se pretende explicar la filosofía de Nietzsche como tal, empresa que ya ha sido realizada con mayor o menor fortuna en innumerables ocasiones, sino tan sólo facilitar la comprensión de algunas paradojas de su filosofía que todavia hoy mantiene perplejos a buena parte de los especialistas, perplejidad que incita, sin duda, hoy lo mismo que ayer y que mañana, a tergiversar los contenidos o a vislumbrar contradicciones en las formas. Tampoco aquí parece que se pretenda lograr una gran resonancia, quizá porque sería muy ingenuo creer que la perplejidad respecto de las mencionadas paradojas, una vez que ésta ha aparecido, pueda resolverse algún día en lucidez. $Y$ en tercer lugar, el carácter tardio de este escrito sobre Nietzsche, que además no quiere ser ni exhaustivo ni vinculante, es una circunstancia que se adecúa bastante bien con la presencia continua de su filosofía en la obra de Rosset, como queda de manifiesto en el hecho de que las "Notas sobre Nietzsche" estén precedidas justamente por el análisis de esa force majeure que es la alegría, el punto neurálgico de la filosofía Rosset y, quizá también -ésa es la tesis-, del propio Nietzsche. En cualquier caso, al margen de su contenido, con este escrito se ilustra un modo particular de concebir la filosofía -consagrada principalmente a destacar el elemento de la alegría y la afirmación-, de la misma manera que "El descontento de Ciorán", el escrito que cierra el libro, e independientemente también de su contenido, ilustra a la perfección el caso contrario, esto es, el inconveniente de haber nacido, la teórica imposibilidad de aclimatarse al tiempo y a la muerte, en suma, a la existencia como tal. No obstante su brevedad y concisión, los puntos en los que se centra el análisis de Rosset tocan de lleno todos los ámbitos de la filosofía nietzscheana, comenzando por el problema histórico de las interpretaciones. Dos grandes dificultades presenta la filosofía de Nietzsche: conciliar la alegría y el conocimiento del dolor, por un lado, y armonizar la aprobación de lo real y la crítica, por el otro. Los analisis de Rosset a este 
respecto son definitivos en tanto que facilitan la comprensión de esa relación jerárquica que, en la obra de Nietzsche, siempre se ha establecido entre la alegría y el conocimiento del dolor, entre la aprobación de lo real y la crítica. En Nietzsche, la alegría dionisíaca siempre triunfa sobre el conocimiento trágico del dolor: es mayor, más fuerte que él, una force majeure en definitiva. A su vez, el conocimiento trágico del dolor es la condición necesaria de la alegría dionisíaca en tanto que la pone a prueba, en tanto que permite justamente a ésta aprobar la realidad con conocimiento de causa. De ahí que esa misma relación jerárquica se establezca, en Nietzsche, entre la aprobación de lo real y la crítica, ocupando aquélla el primer lugar y ésta un lugar secundario. Como se sabe, la mayoría de las interpretaciones de la obra de Nietzsche no hacen sino invertir esta jerarquía. El valor de los análisis de Rosset, por consiguiente, reside principalmente en haber clarificado las posibles dificultades de la filosofía nietzscheana -insalvables desde cualquier tipo de planteamiento racionalista y moral, esto es, metafísico- con la propia filosofía nietzscheana, no en haber anulado dichas dificultades, invirtiendo aquella jerarquía, con una apropiada selección de textos que avale la infame falsificación.

También cabría destacar, por último, una interpretación de la filosofía de Nietzsche que prácticamente ha pasado, está pasando y, a buen seguro, pasará desapercibida, por estar elaborada de espaldas a la sensibilidad filosófica contemporánea y no facilitar, por tanto, el acceso a sus claves interpretativas, a lo que también contribuye la circunstancia de que su autor, Giorgio Colli, no es ni alemán, ni francés, ni anglosajón, razón "geofilosófica" ésta que parece apartarle desgraciadamente de todo buen contacto con la actividad filosófica, tal y como sugieren grandísimas eminencias filosóficas más afortunadas desde este punto de vista, el propio Deleuze $^{28}$ entre ellas. Si se une aquel detalle al hecho de que su autor, que además no pretende en absoluto hacer suyo el pensa-

${ }^{28}$ Cf. G. Deleuze y F. Guatarri, Qu'est-ce que la philosophie?, Les Éditions de Minuit, Paris, 1991. Véase el capítulo "Géophilosophie", págs. 82-108. 
miento de Nietzsche, es sin discusión uno de los mejores conocedores de la vida y la obra del filósofo a lo largo de todo el siglo, y visto el carácter sesgado de la mayor parte de las interpretaciones célebres de Nietzsche, ello haría que pudiera considerarse a Giorgio Colli - poco menos que automáticamente- como uno de los intérpretes más veraces que la filosofía nietzscheana haya tenido nunca. Obras como Después de Nietzsche ${ }^{29}$, aparte de sus cualidades, liberan de Nietzsche del mismo modo que Zaratustra libera de Zaratustra, y es bien sabido que el instinto de rebaño no repara en la forma de los rediles, afectando por igual a "nietzscheanos" y a "hombres superiores" que al resto de los fieles. No es la doctrina, sino la fascinación del nombre asociado a los intereses personales de los fieles, lo que hace que Nietzsche, como cualquier otro ídolo, y por las mismas sinrazones, sea invocado tan a menudo como santo patrón de la filosofía contemporánea. La tarea de Colli, sin duda el más "antiguo" de los pensadores del siglo, más "griego" incluso que el propio filósofo germano, el pensador que con un grado mayor de dureza y libertad se haya acercado hasta la fecha a la obra de Nietzsche, no podía consistir sino en distinguir y mantener separarados al filósofo del comediante, o sea, al filósofo trágico del filósofo decimonónico, a la doctrina racional de los avatares personales, lo que no quiere decir en absoluto que silencie esta última faceta. En general, para Colli, toda la filosofía postsocrática, salvo dos o tres momentos de su historia (Spinoza, Schopenhauer, Nietzsche), es consecuencia de un milenario malentendido de los escritos de Platón, el primer gran racionalista y el inventor de este curioso género literario llamado filosofía. Por lo que respecta a Nietzsche, al decir de Colli, toda su obra se basa en el descubrimiento del pathos dionisíaco inherente a la cultura griega arcaica, siendo el primero en haber comprendido que la

${ }^{29}$ Dopo Nietzsche, Adelphi Edizioni, Milano, 1974. [Trad. cast., Después de Nietzsche, Ed. Anagrama, Barcelona, 1978.] Véase también Scritti su Nietzsche, Adelphi Edizioni, Milano, 1980. Se trata del conjunto de las introducciones a los volúmenes de las Opere complete, escritas entre 1959 y 1978. [Trad. cast., Introducción a Nietzsche, Folios, México, 1983.] 
culminación de la filosofía griega, y de la filosofía como tal, pertenece por derecho propio a los presocráticos. "La doctrina suprema de Nietzsche es una fulguración mística, una visión que libera de cualquier aflicción y de cualquier deseo, incluso de la individuación. Después de esa experiecia todas las ideas, discusiones, doctrinas de Nietzsche no serán más que una comedia de seriedad." ${ }^{130}$ Ahora bien, aunque desde el pensamiento trágico la moral aparezca siempre como una comedia, no puede decirse que ésta no sea un asunto serio. "A Nietzsche se le puede llamar el destructor definitivo de la moral, porque aniquiló el estímulo de la especulación moral, agotó, privó de contenido todos sus conceptos y problemas; por eso fue el gran liberador, el que abrió el camino, el que ahora hace posible una visión "sólo" teorética del mundo." ${ }^{131}$ Dos objeciones cabría hacer aquí a Colli por lo que respecta a éste último punto. En primer lugar, nada parece haber impedido que, tras la crítica de la moral efectuada por Nietzsche, haya habido un renacimiento de la crítica moral propiamente dicha, o mejor aún -si se piensa un poco en la impotencia práctica de toda filosofía, ya sea práctica o teorética, incluso entre los propios filósofos-, nada parece indicar que no haya habido una continuidad sin fisuras del papel predominante de los ídolos en las cabezas de los filósofos moralistas de todas las épocas, exactamente como si Nietzsche no hubiera escrito una sóla línea de filosofía inmoralista. En segundo lugar, nada autoriza a pensar que la crítica de la moral haya tenido que esperar pacientemente los casi 2.500 años de rigor hasta llegar al martillo nietzscheano, no siendo Spinoza quizá la única excepción en la historia de la filosofia en haber emprendido la crítica de lo que jamás puede desaparecer de los espíritus críticos. En cualquier caso, "después de Nietzsche" se recupera, sin duda, las condiciones de la sabiduría o, lo que es idéntico, se desacredita la propia filosofía racionalista y moral, aunque ello sólo sea posible en los casos más afines. En definitiva,

\footnotetext{
${ }^{30}$ Op. cit., ed. cast., p. 151.

${ }^{31}$ Op. cit., ed. cast., p. 64.
} 
dos modos de entender la "filosofía": trágica, pero teorética, y racionalista, pero moral. $Y$ es en aquella dirección, principalmente a partir de la intuición nietzscheana y el estudio de los presocráticos, sin olvidar la atenta lectura de Platón y de Aristóteles en tanto que momentos privilegiados para la observación del nacimiento de la razon constructiva y sistemática, en la que habrá de desarrollar Colli, de espaldas a las preocupaciones de la filosofía actual, toda su ingente y nunca bien ponderada labor intempestiva. "La muerte de la filosofía, precisamente en cuanto se hace evidente su naturaleza mendaz y la causa de dicha naturaleza, deja el camino abierto a la sabiduría. No se trata de cambiar el mundo de la historia: lo que habia antes de la filosofía puede también vivir ahora, $y$ en este terreno -lo que algunos hombres puedan pensar y decirse unos a otros-, los cambios de las sociedades y de los Estados cuentan poco.'132

La sorprendente variedad de los estudios nietzscheanos, según las circunstancias históricas del momento, las directrices de las escuelas, la capacidad y el temperamento de los autores, la mayor o menor relevancia de los temas, variedad que sobrepasa con mucho el estrecho margen de oscilación interpretativa de que disfrutan la mayor parte de los grandes pensadores de todas las épocas, desde Platón a Heidegger, pasando por Aristóteles, Agustín, Tomás, Descartes, Kant, Hegel o Husserl, no puede explicarse en virtud de las peculiaridades estilísticas y doctrinales del propio Nietzsche, como tan a menudo se presupone, al menos no por las razones comúnmente aducidas. Pocos pensadores ha habido en la historia que hayan dicho con mayor claridad lo que querían decir, y quizá ninguno con tanta vehemencia e insistencia. Si no ha sido comprendido, si nadie ha picado en los anzuelos, como decía él mismo de sus contemporáneos, no es culpa suya, es que faltaban los peces... Ciertamente, como dice Colli, Nietzsche ha

${ }^{32}$ Op. cit., ed. cast., p. 59. 
dicho todo y lo contrario de todo. Ahora bien, de esta circunstancia no se infiere en absoluto, como supone Jaspers y toda la moderna dialéctica, que "la auto-contradicción [sea] el rasgo fundamental del pensamiento de Nietzsche" ${ }^{133}$, aunque hay que reconocer que con esta libertad anti-dialéctica se pone a prueba la pericia del interprete para distinguir unos contextos de otros, que es lo primero que se enseña a los niños en la escuela. La condición para entender a Nietzsche, según Colli, es que se le "pueda" entender, esto es, que se le "quiera" entender.

La conclusión que cabe extraer de la variedad y el relativismo que presentan los estudios nietzscheanos no es otra que la confusión en una de las partes, o mejor aún, la imposibilidad de una relación acertada entre las partes. Quizá la confusión esté del lado de Nietzsche, que no acierta a ser un buen metafísico y a explicarse adecuadamente. Pero también puede ser que la confusión recaiga únicamente en los intérpretes por hacer decir a Nietzsche lo que éste no dice, y además con las palabras de los respectivos intérpretes. Algo pasa, sin duda, cuando alrededor de un gran pensador se teje el velo de Maya en forma de olvido (Schopenhauer) o cuando la concurrencia se pelea infructuosamente por ser el primero en despojarlo de sus prendas y todos dicen ser el primero en haberlo logrado (Nietzsche). En este último caso, la variedad infinita de las interpretaciones, que sólo afecta a las características de los intérpretes, no a las múltiples facetas del filósofo, dice también algo del objeto de estudio, siquiera negativamente: o bien Nietzsche no es filósofo en absoluto, y sólo por la utilidad de los escritos se concita un interés polivalente (caso de Marx, según algunos); o bien Nietzsche no es filósofo como la mayoría de los filósofos entienden al filósofo, esto es, no es metafísico, ni dialéctico, ni útil para nada ni para nadie, salvo para otro pensador trágico igualmente inservible en el dominio de las utilidades. Las interpretaciones de Deleuze, Rosset y Colli, tan diferentes entre sí por otra parte, aunque perfectamente comple-

${ }^{33}$ Nietzsche. Introduction à sa philosophie, Gallimard, Paris, 1950, p. 18. 
mentarias -más exhaustiva y especulativa la primera, más filosófica y serena la segunda, más biográfica y mistérica la tercera-, tienen el mérito de haber contribuido, cada una por su lado, a situar la filosofía nietzscheana donde quizá le corresponda, a saber, en la segunda de estas dos alternativas. Con ello queda despejado definitivamente lo que a lo largo de todo el siglo $X X$ se ha ido constituyendo como el enigma "Nietzsche", ya que al parecer son muchos los que piensan que Nietzsche no ha dicho en todas y cada una de sus obras, con nitidez y hasta la saciedad, justamente lo que quería decir. En cualquier caso, como diría el filósofo adivino, ahora ya sólo faltan los peces... 